\title{
The structure of alkyl ester sulfonate surfactant micelles: the impact of different valence electrolytes and surfactant structure on micelle growth.
}

Zi Wang ${ }^{1,2}$, Peixun $\mathrm{Li}^{2}$, Kun $\mathrm{Ma}^{2}$, Yao Chen ${ }^{2}$, Jeffrey Penfold ${ }^{2,3, !}$, Robert K Thomas ${ }^{3}$, David W Roberts ${ }^{4}$, Hui Xu ${ }^{5}$, Jordan T Petkov ${ }^{6}$, Zifeng Yan ${ }^{1, !}$, Diego Alba Venero ${ }^{2}$

1. School of Science, State Key Laboratory of Heavy Oil Processing, China University of Petroleum, Qingdao 266580, China

2. ISIS Facility, Rutherford Appleton Laboratory, STFC, Didcot, OXON, UK, OX11 0QX

3. Physical and Theoretical Chemistry Laboratory, Oxford University, South Parks Road, Oxford, UK, OX1 3QZ

4. School of Pharmacy and Biomolecular Sciences, Liverpool John Moores University, Liverpool, L3 3AF, UK

5. KLK Oleo, SDN BDH, Menara KLK, Muliara Damansara, 47810 Petaling, Jaya Selanger, Malaysia

6. Lonza UK, GB-Blackley, Manchester, Lancs, M9 8ES, UK

! Joint Corrresponding Authors: Jeff Penfold, email: jeff.penfold@stfc.ac.uk, Yan Zifeng, email: zfyancat@upc.edu.cn

Keywords: ester sulfonate anionic surfactants, self-assembly, micellar growth, small angle neutron scattering 


\begin{abstract}
The ester sulfonate anionic surfactants are a potentially valuable class of sustainable surfactants. The micellar growth, associated rheological changes, and the onset of precipitation are important consequences of the addition of electrolyte and especially multi-valent electrolytes in anionic surfactants

Small angle neutron scattering, SANS, has been used to investigate the self-assembly and the impact of different valence electrolytes on the self-assembly of a range of ester sulfonate surfactants with subtly different molecular structures.

The results show that in the absence of electrolyte small globular micelles form, and in the presence of $\mathrm{NaCl}$, and $\mathrm{AlCl}_{3}$ relatively modest micellar growth occurs before the onset of precipitation. The micellar growth is more pronounced for the longer unbranched and branched alkyl chain lengths. Whereas changing the headgroup geometry from methyl ester to ethyl ester has in general a less profound impact. The study highlights the importance of relative counterion binding strengths and shows how the surfactant structure affects the counterion binding and hence the micelle structure. The results have important consequences for the response of such surfactants to different operational environments.
\end{abstract}




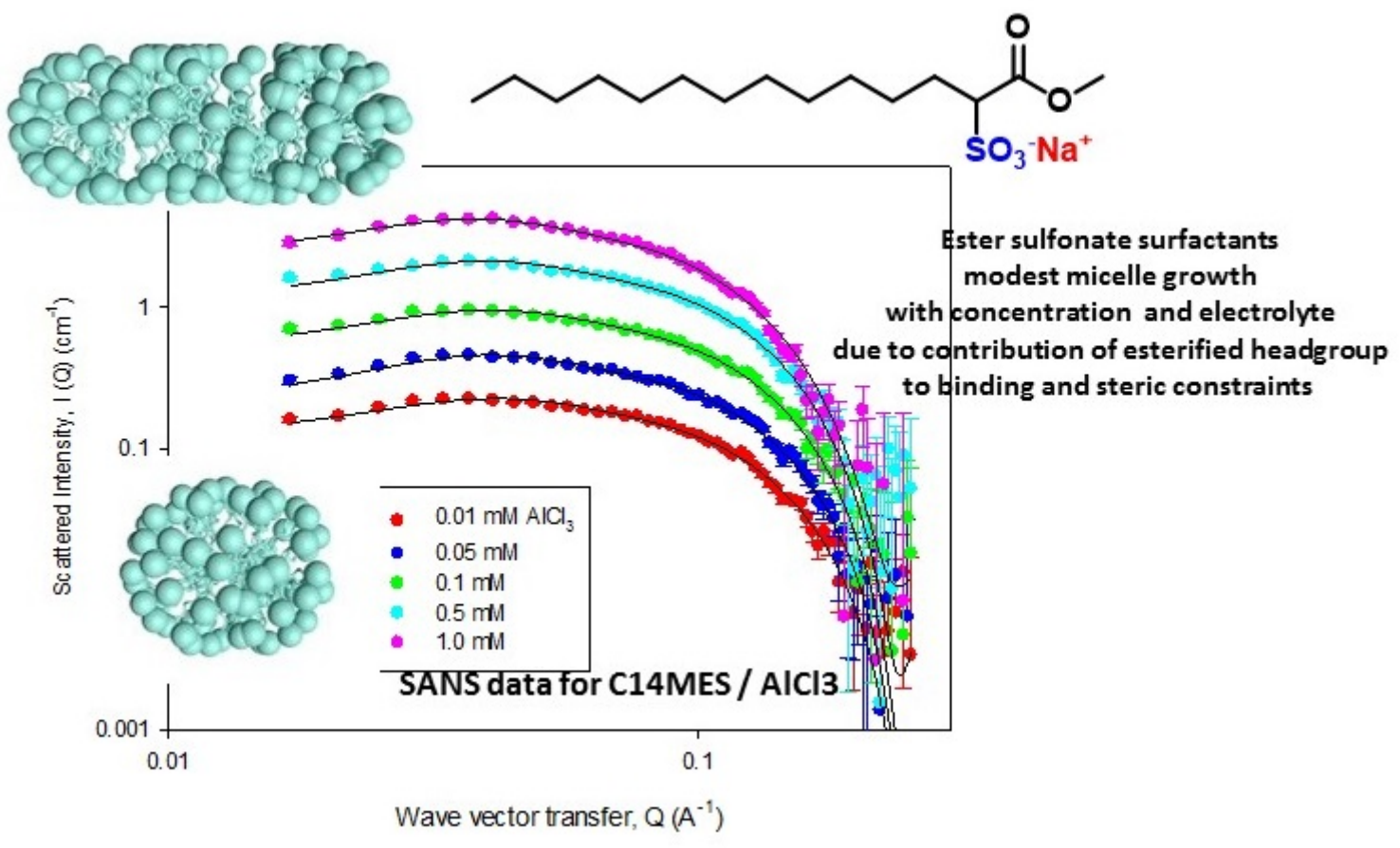




\section{INTRODUCTION}

The effect of different valence electrolytes on the self-assembly and adsorption of anionic surfactants can have a significant impact upon their performance in applications where anionic surfactants are a major component $(1,2)$. For synthetic surfactants this has resulted in the development of a wide range of molecular structures for the purpose of optimising their response and performance in the different operational environments that are generated by electrolyte and other additives which affect solvent quality (2). However, in addition a major and developing theme in the exploitation of surfactants is in the development of biosustainable and biodegradable surfactants (3-5) and especially in the production of surfactants from sustainable sources (6). The methyl ester sulfonate surfactants and their variations are an exciting and relatively recent development of biosustainable surfactants $(7,8)$, and have been shown to meet many of the requirements for a range of applications,

The addition of electrolytes, such as $\mathrm{NaCl}$, promote micellar growth, induce phase changes, reduce critical micelle concentrations, $\mathrm{cmc}$, and enhance adsorption at interfaces (9-11). The effect of the addition of multivalent counterions, such as $\mathrm{Ca}^{2+}$ or $\mathrm{Al}^{3+}$, can have an even more profound effect. For surfactants such as sodium dodecyl sulfate, SDS, this leads rapidly to precipitation $(12,13)$, which gives rise to many difficulties, such as reduced detergency in hard water environments, and is associated with many environmental applications, such as soil remediation and heavy metal extraction (14-16). The alkyl sulfates, such as SDS, are especially sensitive to precipitation in the presence of multivalent electrolytes. This is enhanced for the longer alkyl chain lengths as the surfactants become intrinsically less soluble (12). The addition of a non-ionic co-surfactant may mitigate many of the undesirable effects (14). However an increasing range of different anionic surfactant structures have been developed in attempts to overcome these issues $(1,2)$. These include the alkyl benzene sulfonates, LAS, (12-16) and the oligoethylene glycol monoalkyl ether sulfates, SAES, surfactants (17-20).

More recently the alkyl methyl ester sulfonate, MES, surfactants $(7,8,21,22)$ have been shown to be a potential replacement for anionic surfactants such as the alkly sulfates, LAS and SAES surfactants. These have the attraction of biosustainability, in addition to their greater tolerance to multivalent counterions and a good low temperature performance, (23-37). Although the synthesis and associated purification of the MES surfactants have been extensively studied and 
reported (32-41), reports of their self-assembly and adsorption properties are less common $(42-45)$.

The addition of multivalent counterions is now well established to result in the formation of ordered multilayer structures at the air-water interface for a range of anionic surfactants. For example, it has been observed for LAS and LAS / non-ionic surfactant mixtures with $\mathrm{Ca}^{2+}(46-$ 48), and for the SAES surfactants with $\mathrm{Al}^{3+}$ (49-52). In such cases the strong binding and bridging across adjacent surfactant layers of the multivalent counterion results in the attractive force that is required to form a concentrated lamellar structure at the interface from dilute solution, but which often occurs outside the regime of concentrated lamellar precipitation in the bulk solution. This has recently also been demonstrated in the MES surfactants (36-45), in the surface properties of the ester sulfonate surfactants in the presence of different counterions (45), and in the structural changes of the alkyl chain and headgroup (53).

The self-assembly properties of these ester sulfonate surfactants and how they are affected by the presence of multivalent electrolytes are, however, equally important in the context of their potentially diverse applications. Although some aspects of micellar growth due to the addition of divalent electrolytes and other additives is well established (10,17-19), it continues to be an active area of investigation because of its importance and diversity of effects (54-57). Importantly it has been less extensively studied and reported for the AES surfactants $(21,41$, 44). The focus of this paper is to address this shortcoming. The investigation of the impact of electrolyte on the self-assembly of a range of ester sulfonate surfactants, AES, with different molecular structures, is reported. Specifically we report here the impact of $\mathrm{NaCl}$, and $\mathrm{AlCl}_{3}$ on the self-assembly of ester sulfonate surfactants, with varying alkyl chain lengths from $\mathrm{C}_{14}$ to $\mathrm{C}_{16}$, for a branched isostearic alkyl chain and for different degrees of esterification from methyl to propyl, using small angle neutron scattering, SANS .

\section{EXPERIMENTAL DETAILS}

The SANS measurements were made on two different diffractometers, LOQ (58), and SANS2D (59), at the ISIS pulsed neutron source. These give the scattered intensity, I(Q), as a function of the scattering vector, $Q$, where $Q$ is defined as $Q=(4 \pi / \lambda) \sin \theta, 2 \theta$ is the scattering angle and $\lambda$ the neutron wavelength. Further details of the instrument parameters and data reduction procedures are given elsewhere $(60,61)$ and in the Supporting Information.

The measurements were made in $\mathrm{D}_{2} \mathrm{O}$ using surfactants in their unlabelled hydrogenated form to maximise the scattered intensity. At the low solution concentrations used in this study, the 
finite background subtraction and beam spill around the beam stop limits the usable Q range to $\sim 0.01$ to $0.25 \AA^{-1}$. Each scattering profile was measured for $\sim 15$ to 40 minutes, depending upon the diffractometer and the sample concentration, to obtain significant statistical quality.

The form of the scattering, I(Q), was used to identify the regions of phase space where micelle structures exist and the transition to a precipitated concentrated lamellar phase. The purely micellar regions were quantitatively analysed as globular interacting, or elongated micelles, using a standard model (62), which is described in more detail in the Supporting Information.

The key adjustable model parameters are $v$, the micelle aggregation number, and $\mathrm{z}$, the micelle charge. The degree of ionisation of the micelle, $\delta$, is defined as $\delta=\mathrm{z} / v$. The model is compared with the experimental data and evaluated by least squares. A fit is deemed acceptable if the functional form of the data is reproduced to within $20 \%$ of the absolute scaling. Although the solvent and cell background scattering are subtracted an additional background is often required in the model fitting to the data due to incomplete subtraction of the background scattering.

Five different ester sulfonate surfactants were studied. The surfactants were sodium tetradecanoic 2-sulfo 1-methyl ester, $\mathrm{C}_{14} \mathrm{MES}$, sodium tetradecanoic 2-sulfo 1-ethyl ester, $\mathrm{C}_{14} \mathrm{EES}$, sodium tetradecanoic 2-sulfo 1-propyl ester, $\mathrm{C}_{14} \mathrm{PES}$, sodium hexadecanoic 2-sulfo 1ethyl ester, $\mathrm{C}_{16} \mathrm{EES}$, and sodium isostearic 2-sulfo 1-methyl ester, iso $\mathrm{C}_{18} \mathrm{MES}$. Their structures are shown in figure 1 . The iso $\mathrm{C}_{18} \mathrm{MES}$ is shown as a single isomer, but is a mixture of branched isomers.

The procedure for the synthesis and purification of $\mathrm{C}_{14} \mathrm{MES}$ has previously been described (28), and the same process was followed for the other surfactants investigated here. Direct sulfonation of tetradecanoic methyl (ethyl, propyl) ester, hexadecanoic ethyl ester and isostearic methyl ester by $\mathrm{SO}_{3}$ introduced from the vapour phase was used for the preparation of the methyl esters, but the other propyl, ethyl and methyl esters were produced using the slightly different route of sulfonation of the tetradecanoic, hexadecanoic and isostearic acids and esterification with ethanol, methanol and propanol. From surface tension and NMR the purity of these custom synthesised surfactants is at least $>99.5 \%$ as previously discussed(42, $53)$.

Deuterium oxide, $\mathrm{D}_{2} \mathrm{O}$, Sigma Aldrich, high purity water (resistivity of $18.2 \mathrm{M} \Omega \mathrm{cm}$ ) and analytical grade ( $>99.9 \%$ purity) $\mathrm{NaCl}$, and $\mathrm{AlCl}_{3}$, Sigma Aldrich, were used in the solution preparation. All the glassware associated with sample preparation and the SANS 
spectrophotometer cells were cleaned in alkali detergent (Decon90) and extensively rinsed in ultrapure water. No adjustments for $\mathrm{pH}$ were made in the presence of electrolyte.

SANS measurements were made for $\mathrm{C}_{14} \mathrm{MES}, \mathrm{C}_{14} \mathrm{EES}, \mathrm{C}_{14} \mathrm{PES}, \mathrm{C}_{16} \mathrm{EES}$ and isoC ${ }_{18} \mathrm{MES}$ at surfactant concentrations of 5,10 , and $20 \mathrm{mM}$ with no added electrolyte. In $\mathrm{NaCl}$ measurements were made for all five surfactants at 5, 10, and $20 \mathrm{mM}$, except for $\mathrm{C}_{14} \mathrm{MES}$ which was measured at 5 and $10 \mathrm{mM}$ only. For $\mathrm{C}_{14} \mathrm{MES}$ the measurements were made at $\mathrm{NaCl}$ concentrations of 5,10,20,50 and $100 \mathrm{mM}$, whilst the other surfactants were measured at a fixed $\mathrm{NaCl}$ concentration of $100 \mathrm{mM}$. With $\mathrm{AlCl}_{3} \mathrm{C}_{14} \mathrm{MES}$ was measured at surfactant concentrations of 5,10 and $20 \mathrm{mM}$, and $\mathrm{AlCl}_{3}$ concentrations of $0.01,0.05,0.1,1.0,2.0,4.0$ and $5.0 \mathrm{mM}$. The other four surfactants were measured at surfactant concentrations of 5,10 and $20 \mathrm{mM}$ and $\mathrm{AlCl}_{3}$ concentrations of $0.1,0.5,1.0,2.0,4.0$ and $5.0 \mathrm{mM}$.

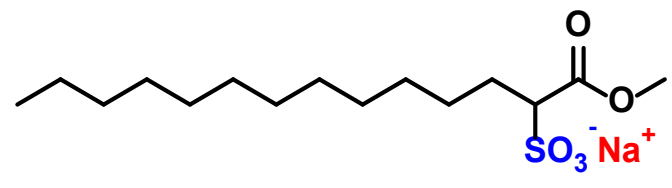

(a)

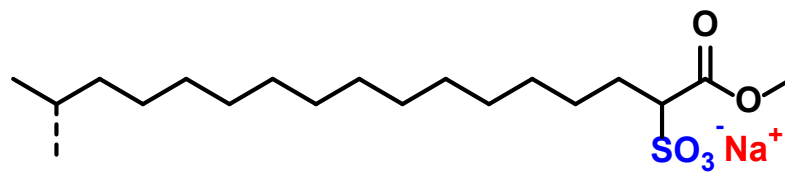

(c)

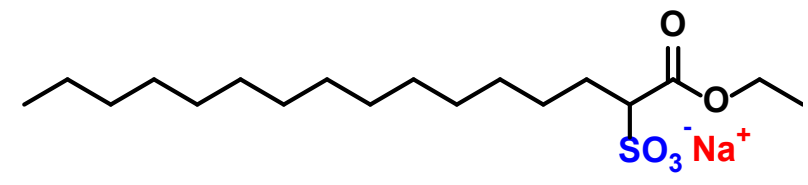

(e)<smiles>CCCCCCCCCCCCC(C(=O)OCC)[Sb]([O])([O-])[O-]</smiles>

(b)

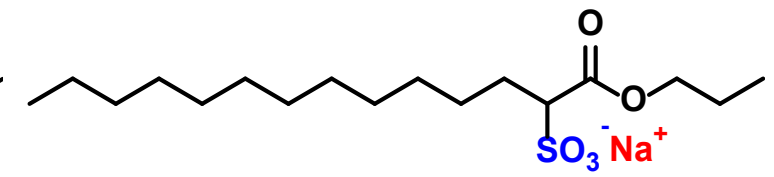

(d)

Figure 1. Molecular structure of (a) $C_{14} M E S$, (b) $C_{14} E E S$, (c) iso $C_{18} M E S$, (d) $C_{14} P E S$ and (e) $C_{16} E E S$

The associated critical micelle concentrations, cmc, values for $\mathrm{C}_{14} \mathrm{MES}, \mathrm{C}_{14} \mathrm{EES}, \mathrm{C}_{14} \mathrm{PES}$, $\mathrm{C}_{16} \mathrm{EES}$ and isoC ${ }_{18} \mathrm{MES}$ are $2.4 \mathrm{mM}, 2.06 \mathrm{mM}, 0.93 \mathrm{mM}, 0.48 \mathrm{mM}$ and $0.59 \mathrm{mM}$ respectively $(42-45,53)$. Hence the SANS measurements at the lowest surfactant concentration, $5 \mathrm{mM}$, are in some cases relatively close to the $\mathrm{cmc}$. In electrolyte the cmc values reduce significantly; for example, the cmc of $\mathrm{C}_{14} \mathrm{MES}$ and isoC ${ }_{18} \mathrm{MES}$ in $0.1 \mathrm{M} \mathrm{NaCl}$ are 0.16 and $0.01 \mathrm{mM}$ respectively. 


\section{RESULTS}

\section{(a) Self-assembly in the absence of electrolyte}

SANS measurements were initially made at surfactant concentrations of 5, 10 and $20 \mathrm{mM}$ for $\mathrm{C}_{14} \mathrm{MES}, \mathrm{C}_{14} \mathrm{EES}, \mathrm{C}_{14} \mathrm{PES}, \mathrm{C}_{16} \mathrm{EES}$ and isoC ${ }_{18} \mathrm{MES}$ in $\mathrm{D}_{2} \mathrm{O}$ and in the absence of electrolyte. The data for $\mathrm{C}_{14} \mathrm{MES}, \mathrm{C}_{14} \mathrm{EES}$ and $\mathrm{C}_{16} \mathrm{EES}$ are shown in figure 2. The data for $\mathrm{C}_{14} \mathrm{PES}$ and iso $\mathrm{C}_{18} \mathrm{MES}$ are broadly similar and are not shown. The data are consistent with the scattering from globular interacting micelles, and are well represented by the model described earlier. The key fitting parameters for the data in figure 2 are summarised in table 1 , and for $\mathrm{C}_{14} \mathrm{PES}$ and iso $\mathrm{C}_{18} \mathrm{MES}$ in table $\mathrm{S} 1$ in the Supporting Information.

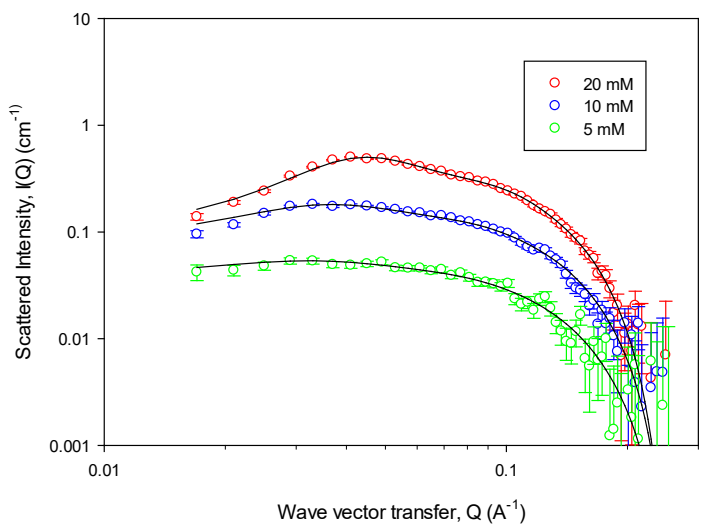

(a)

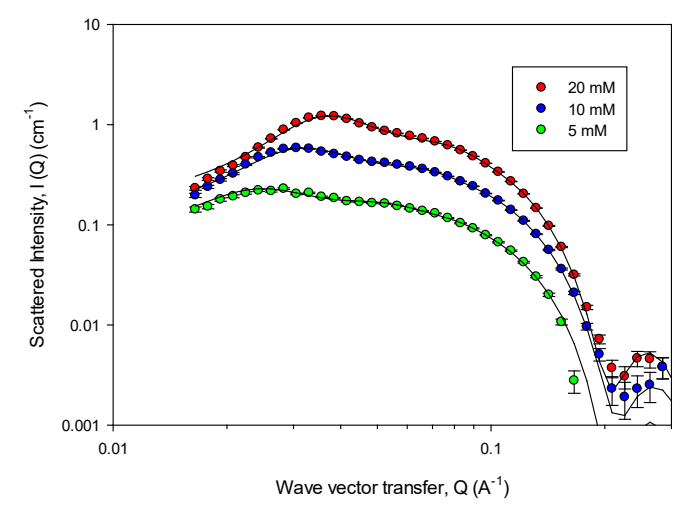

(c)

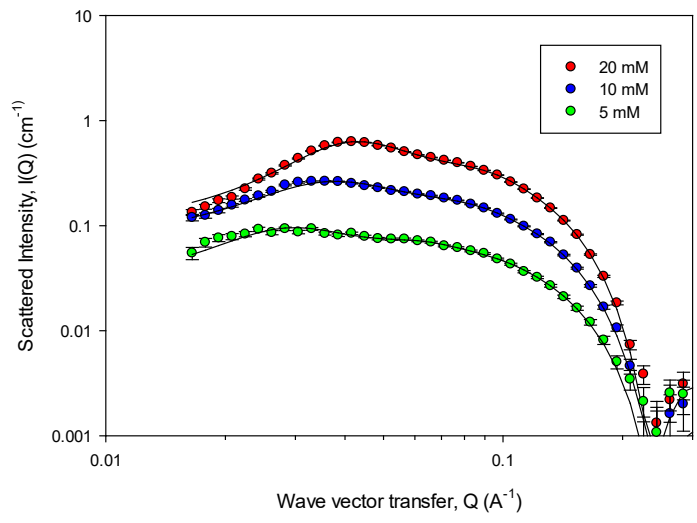

(b)

Figure 2. Scattered Intensity, $I(Q)$, versus wave vector transfer, $Q$, for (a) $C_{14} M E S$, (b) $C_{14} E E S$, and (c) $C_{16} E E S$, see legends for details. The solid lines are model calculations, as described in the text, and for the key model parameters summarised in table 1. 
Table 1. Key model parameters from core + shell model fits to SANS data for (a) $C_{14} M E S$, (b) $C_{14} E E S$, and (c) $C_{16} E E S$,

(a) $C_{14} M E S$

\begin{tabular}{|c|c|c|c|c|c|}
\hline $\begin{array}{c}\text { Surfactant } \\
\text { concentration } \\
(\mathbf{m M})\end{array}$ & $\begin{array}{c}\text { Aggregation } \\
\text { number, } \mathbf{v}, \\
\mathbf{\pm 5}\end{array}$ & $\begin{array}{c}\text { Micelle } \\
\text { charge, } \mathbf{z}, \\
\pm \mathbf{3}\end{array}$ & $\begin{array}{c}\text { Degree of } \\
\text { ionisation, } \\
\boldsymbol{\delta}, \pm \mathbf{0 . 0 3}\end{array}$ & $\begin{array}{c}\text { Ellipticity, } \\
\mathbf{e e , ~} \mathbf{\pm 0 . 0 2}\end{array}$ & $\begin{array}{c}\text { Scale } \\
\text { factor, } \mathbf{s f}\end{array}$ \\
\hline 5 & 58 & 27 & 0.46 & 1.00 & 1.04 \\
\hline 10 & 62 & 23 & 0.37 & 1.03 & 1.07 \\
\hline 20 & 65 & 20 & 0.31 & 1.09 & 1.03 \\
\hline
\end{tabular}

(b) $C_{14} E E S$

\begin{tabular}{|c|c|c|c|c|c|}
\hline $\begin{array}{c}\text { Surfactant } \\
\text { concentration } \\
(\mathbf{m M})\end{array}$ & $\begin{array}{c}\text { Aggregation } \\
\text { number, } \mathbf{v}, \\
\pm \mathbf{5}\end{array}$ & $\begin{array}{c}\text { Micelle } \\
\text { charge, } \mathbf{z}, \\
\mathbf{\pm 3}\end{array}$ & $\begin{array}{c}\text { Degree of } \\
\text { ionisation, } \\
\boldsymbol{\delta}, \pm \mathbf{0 . 0 3}\end{array}$ & $\begin{array}{c}\text { Ellipticity, } \\
\mathbf{e e ,} \pm \mathbf{0 . 0 2}\end{array}$ & $\begin{array}{c}\text { Scale } \\
\text { factor, } \mathbf{s f}\end{array}$ \\
\hline 5 & 58 & 60 & 1.00 & 1.00 & 1.06 \\
\hline 10 & 68 & 31 & 0.46 & 1.14 & 1.06 \\
\hline 20 & 73 & 27 & 0.37 & 1.22 & 0.97 \\
\hline
\end{tabular}

(c) $C_{16} E E S$

\begin{tabular}{|c|c|c|c|c|c|}
\hline $\begin{array}{c}\text { Surfactant } \\
\text { concentration } \\
(\mathbf{m M})\end{array}$ & $\begin{array}{c}\text { Aggregation } \\
\text { number, } \mathbf{v}, \\
\pm \mathbf{5}\end{array}$ & $\begin{array}{c}\text { Micelle } \\
\text { charge, } \mathbf{z}, \\
\mathbf{\pm 3}\end{array}$ & $\begin{array}{c}\text { Degree of } \\
\text { ionisation, } \\
\boldsymbol{\delta}, \pm \mathbf{0 . 0 3}\end{array}$ & $\begin{array}{c}\text { Ellipticity, } \\
\mathbf{e e ,} \pm \mathbf{0 . 0 2}\end{array}$ & $\begin{array}{c}\text { Scale } \\
\text { factor, sf }\end{array}$ \\
\hline 5 & 95 & 100 & 1.00 & 1.24 & 0.94 \\
\hline 10 & 62 & 59 & 0.62 & 1.21 & 0.91 \\
\hline 20 & 104 & 41 & 0.37 & 1.33 & 0.94 \\
\hline
\end{tabular}

At the lowest surfactant concentration measured the scattering is largely dominated by the micelle form factor, $F(Q)$. As the surfactant concentration increases, the peak in the scattering, 
which is due to the contribution from the inter-micellar interactions and described by $S(Q)$, becomes more pronounced.

For $\mathrm{C}_{14} \mathrm{MES}, \mathrm{C}_{14} \mathrm{EES}$ and $\mathrm{C}_{14} \mathrm{PES}$ the micelle aggregation number, $v$, varies from $\sim 60$ to $\sim 75$, for methyl to ethyl to propyl and as the surfactant concentration increases from 5 to $20 \mathrm{mM}$. From the constraints in the model the radius of inner core of the micelle, $\mathrm{r}_{1}$, is $\sim 17 \AA$, and the outer radius, $\mathrm{r}_{2}$, is $\sim 21 \AA$. At these relatively low aggregation numbers the micelles are only slightly elliptical, and the ellipticity varies from 1.0 to $\sim 1.3$. Although close to the uncertainty in the fitting, the aggregation number shows a systematic increase with concentration for $\mathrm{C}_{14} \mathrm{MES}, \mathrm{C}_{14} \mathrm{EES}$ and $\mathrm{C}_{14} \mathrm{PES}$. Although the increase is small, it is more pronounced for $\mathrm{C}_{14} \mathrm{EES}$ and $\mathrm{C}_{14} \mathrm{PES}$ compared with $\mathrm{C}_{14} \mathrm{MES}$. Apart from the concentration dependence of the aggregation number, changing the headgroup from methyl to propyl has only a modest impact upon the micelle size. These relatively subtle changes in the headgroup geometry and subsequent micelle aggregation are consistent with the observations of the self-assembly of the SAE surfactants, the comparable change in the related sodium polyethylene glycol monododecyl ether sulfates, SLES, of increasing the number of ethylene oxide groups from 1 to 3 had only a minimal impact upon the micelle aggregation in the SLES (64). The SAE observation is also opposite to observations for the polyoxyethene non-ionic surfactants, where increasing the ethylene oxide group size results in more globular structures (65). This shows that increasing the esterification of the headgroup within this range has minimal impact upon the micellar packing. The modest change in the micelle structure with changes in esterification are consistent with observations of the packing at the air-water interface, where increasing the esterification from methyl to ethyl does not significantly alter the saturation adsorption (53).

Increasing the alkyl chain length has a more significant impact upon the micelle aggregation. For $\mathrm{C}_{16} \mathrm{EES}$ and isoC ${ }_{18} \mathrm{MES}$ the micelle aggregation number now varies from $\sim 95$ to 105 for $\mathrm{C}_{16} \mathrm{EES}$ and is $\sim 150$ for iso $\mathrm{C}_{18} \mathrm{MES}$. Again the increase in the aggregation number with increasing surfactant concentration is modest, see table S1 in the Supporting Information. The corresponding micelle ellipticity values now vary from $\sim 1.2$ to $\sim 1.5$. The changed molecular constraints mean that the corresponding $\mathrm{r}_{1}$ and $\mathrm{r}_{2}$ values are $\sim 19$ and $23 \AA$ for $\mathrm{C}_{16}$ EES and $\sim$ 22 and $26 \AA$ for iso $\mathrm{C}_{18} \mathrm{MES}$. Measurements of the adsorption and self-assembly of the longer alkyl chain length MES surfactants were reported by Xu et al (30). The SANS measurements in that study were only made on the eutectic mixture of $\mathrm{C}_{16} \mathrm{MES}$ and $\mathrm{C}_{18} \mathrm{MES}$ due to Krafft point limitations in the pure components. However for a 65 / 35 mole ratio mixture of $\mathrm{C}_{16} \mathrm{MES}$ and $\mathrm{C}_{18} \mathrm{MES}$ and at a surfactant concentration from 5 to $20 \mathrm{mM}$ the aggregation number varies 
from $\sim 115$ to $\sim 125$. The results presented here (see tables S1 in the Supporting Information) are reasonably consistent with those observations. The increase in the aggregation number with increasing alkyl chain length is also broadly consistent with previous observations for a range of other ionic surfactants $(10,62)$.

The other important key parameter from the data analysis, which is one that largely determines the nature of the inter-micelle interactions, is the degree of counterion binding, expressed here as the micelle charge, $\mathrm{z}$, or the degree of ionisation, $\delta$, where $\delta=\mathrm{z} / \mathrm{v}$. For all the five surfactants studied here $\delta$ at the lowest surfactant concentration, $5 \mathrm{mM}$, is $\sim 1.0$, i.e. the micelle is fully ionised. This is expected because for the $\mathrm{C}_{14}$ alkyl chain length surfactants a surfactant concentration of $5 \mathrm{mM}$ is only a factor 2 greater than the $\mathrm{cmc}$, and for the $\mathrm{C}_{16}$ and iso $\mathrm{C}_{18}$ surfactants it is $\sim 5$ to 10 times the cmc (53). As the surfactant concentration increases $\delta$ decreases to a value of $\sim 0.3$ to 0.4 at $20 \mathrm{mM}$, and this is broadly in line other experimental observations (62). Implicit in the law of mass action for micelle formation (67) and theories dealing with counterion binding $(66,68)$, the micelles that form close to the cmc are highly ionised and the degree of ionisation decreases as the surfactant and electrolyte concentrations increase. This is what is qualitatively observed here, and the results presented are broadly consistent with theoretical predictions (66). The values at $20 \mathrm{mM}$ are also consistent with those reported for SDS and a range of other ionic surfactants $(62,66)$. Notably the values of $\delta$ increase as the degree of esterification increases from methyl to propyl. Hence, although the degree of esterification has relatively little impact upon the micellar packing and hence its aggregation number, it does result in a decrease in the strength of the ion binding, resulting in a more highly charged micelle. This is different, for example, to the observation of the counterion binding in the SAES micelles, where the presence of the ethylene oxide group resulted in a more weakly ionised micelle, with a much lower degree of ionisation, $\leq 0.15$, compared to other anionic surfactants (49). In that case the stronger ion binding was attributed to the ethylene oxide groups modifying the local dielectric constant and hence the intra-headgroup interactions. Here the increasing esterification has the opposite effect and in particular increases counterion binding. However the effect is not sufficient to affect the micelle aggregation significantly. When considering the different contributions to the free energy of micellisation, in the Molecular Thermodynamics approach $(69,70)$ the two main headgroup contributions for ionic surfactants are electrostatic and steric terms. Penfold et al (71) showed for an anionic / nonionic surfactant mixture how these relative contributions can affect the variation in micelle aggregation number. The results for the AES surfactants, without and in the presence of 
electrolyte (see later), are consistent with the steric contribution dominating over the electrostatic contribution.

\section{(b) Self-assembly in $\mathrm{NaCl}$}

Limited SANS measurements were made for the surfactants in $\mathrm{NaCl}$, but under slightly different conditions. The measurements for $10 \mathrm{mM} \mathrm{C}_{14} \mathrm{MES}$ in $\mathrm{NaCl}$ were made at $\mathrm{NaCl}$ concentrations from 5 to $100 \mathrm{mM}$, and the corresponding data are shown in figure 3 with the key model parameters summarised in table S2. The data show a gradual increase in the scattering at low $\mathrm{Q}$ values with increasing $\mathrm{NaCl}$ concentration, consistent with the formation of longer more elongated structures. However the detailed analysis shows that the micelle growth is modest and the micelle aggregation number has increased from $\sim 60$ in the absence of electrolyte to $\sim 80$ in $100 \mathrm{mM} \mathrm{NaCl}$. This corresponds to an increase in the ellipticity from $\sim 1.05$ to 1.4 , and is also associated with a decrease in the net charge on the surface of the micelle.

The micelle properties for $\mathrm{C}_{14} \mathrm{EES}, \mathrm{C}_{14} \mathrm{PES}, \mathrm{C}_{16} \mathrm{EES}$ and iso $\mathrm{C}_{18} \mathrm{MES}$ in the presence of $\mathrm{NaCl}$ were measured at $100 \mathrm{mM} \mathrm{NaCl}$ only, but at surfactant concentrations of 5, 10, and $20 \mathrm{mM}$, and additional measurements were made for $\mathrm{C}_{14} \mathrm{MES}$ at $5 \mathrm{mM}$ surfactant. These data allow a direct comparison between the different surfactant structures at a surfactant concentration of $10 \mathrm{mM}$ and in $100 \mathrm{mM} \mathrm{NaCl}$. The key fitting parameters are summarised in table $\mathrm{S} 3$ in the Supporting Information.

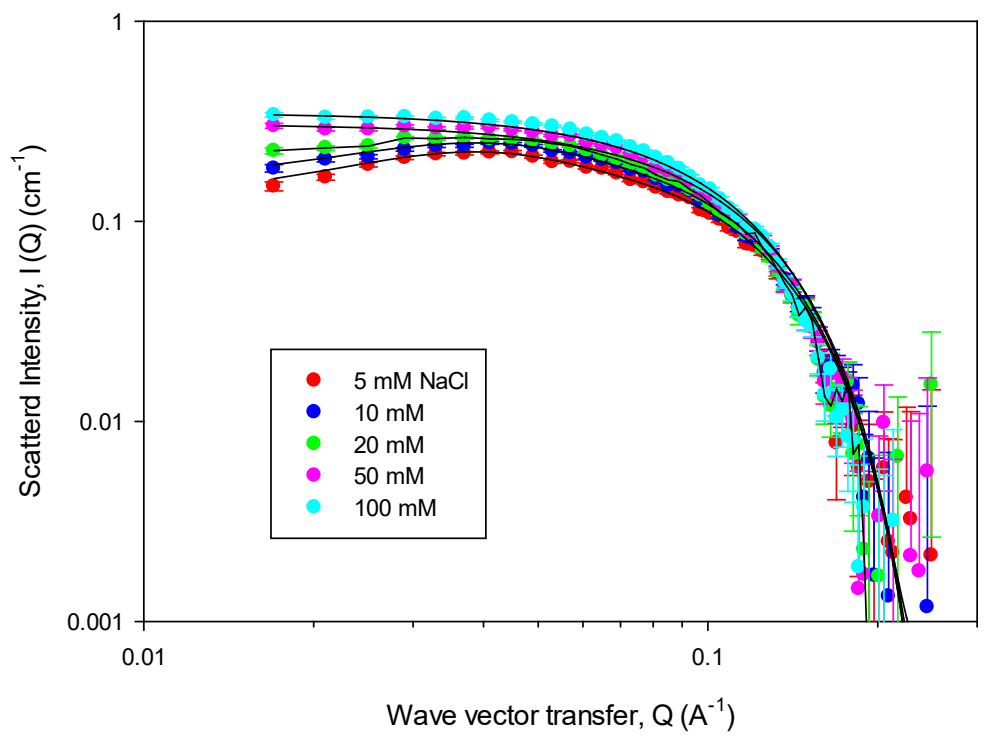


Figure 3. Scattered Intensity, $I(Q)$, versus wave vector transfer, $Q$, for $10 \mathrm{mM} C_{14} M E S$ in $\mathrm{NaCl}$, see legend for details. The solid lines are model calculations, using the model described in the text, and for the key model parameters summarised in table S2.

In the presence of $\mathrm{NaCl}$ the increase in the micelle aggregation number is more significant for the $\mathrm{C}_{14}$ ethyl and propyl ester sulfonates than for $\mathrm{C}_{14} \mathrm{MES}$; where the mean increase is $\sim 1.7$ compared to $\sim 1.3$ for $\mathrm{C}_{14} \mathrm{MES}$. This coincides with the higher degree of ionisation for those surfactants compared to $\mathrm{C}_{14} \mathrm{MES}$, and implies more effective $\mathrm{Na}^{+}$binding in the presence of $\mathrm{NaCl}$, even though the binding is weaker in the absence of $\mathrm{NaCl}$. For the iso $\mathrm{C}_{18} \mathrm{MES}$, which had the largest aggregation number at $10 \mathrm{mM}$ in the absence of $\mathrm{NaCl}$, the greater tendency towards more elongated structures for iso $\mathrm{C}_{18} \mathrm{MES}$ is more strongly promoted by the addition of electrolyte.

\section{(c) Self-assembly in $\mathrm{AlCl}_{3}$.}

SANS measurements were made for $\mathrm{C}_{14} \mathrm{MES}, \mathrm{C}_{14} \mathrm{EES}, \mathrm{C}_{14} \mathrm{PES}, \mathrm{C}_{16} \mathrm{EES}$ and iso $\mathrm{C}_{18} \mathrm{MES}$ at surfactant concentrations of 5,10 and $20 \mathrm{mM}$ and for $\mathrm{AlCl}_{3}$ concentrations ranging from 0.01 to $5 \mathrm{mM}$. The SANS data for $10 \mathrm{mM} \mathrm{C}_{14} \mathrm{MES}, \mathrm{C}_{14} \mathrm{EES}$ and $\mathrm{C}_{16} \mathrm{EES}$ are shown in figure 4 . The data in figure 4 show the scattering from surfactant / $\mathrm{AlCl}_{3}$ mixtures which are still micellar. The physical appearance of the solutions, in the concentration range 5 to $20 \mathrm{mM}$, are clear solutions up to $\mathrm{AlCl}_{3}$ concentrations $\sim 2 \mathrm{mM}$. In these concentration ranges they showed no signs of the turbidity that would be associated with more substantial micellar growth. Between $\mathrm{AlCl}_{3}$ concentrations of 2 to $5 \mathrm{mM}$, the solutions vary from clear to cloudy in appearance, but all show signs of precipitation. At this point the form of the scattering changes dramatically from the patterns shown in figure 4, to that associated with a concentrated lamellar phase or complete precipitation. This is shown in figure S1 in the Supporting Information for $10 \mathrm{mM}$ $\mathrm{C}_{14} \mathrm{EES}$ as a function of $\mathrm{AlCl}_{3}$ concentration. Whether a concentrated lamellar component forms or complete precipitation occurs depends upon the surfactant, surfactant and $\mathrm{AlCl}_{3}$ concentrations. The trends observed here are summarised in table S4 in the Supporting Information, and are consistent with those reported for the SAES surfactants $(52,64)$. 


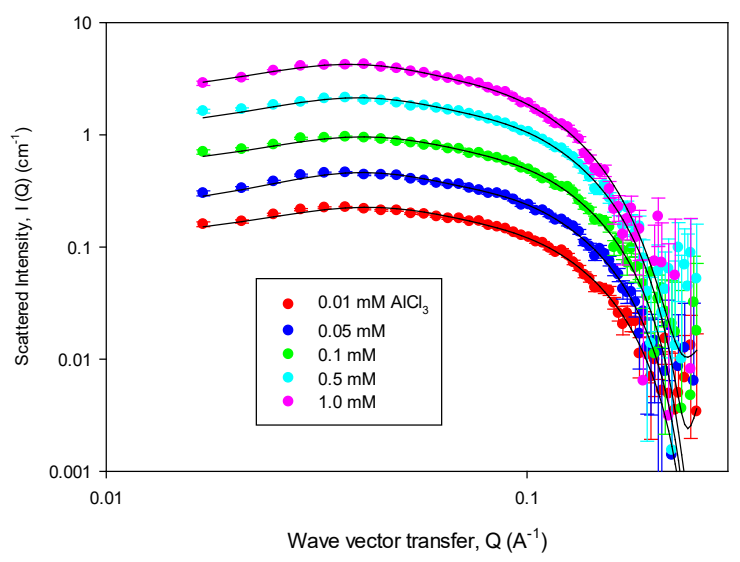

(a)

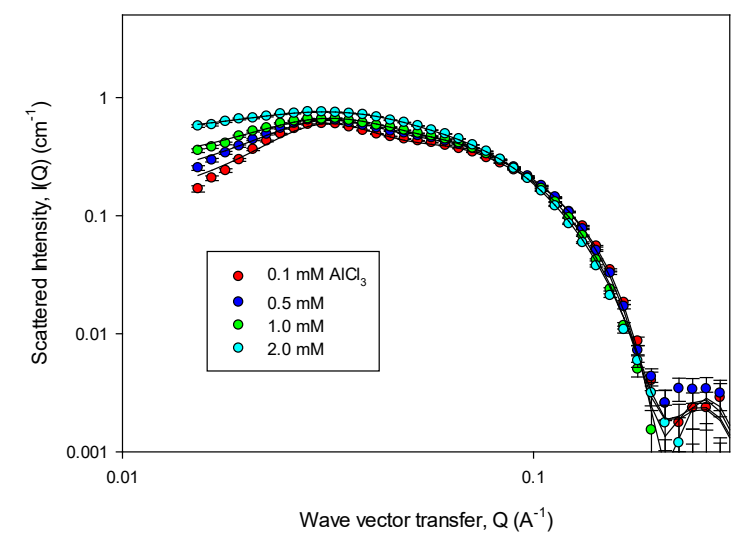

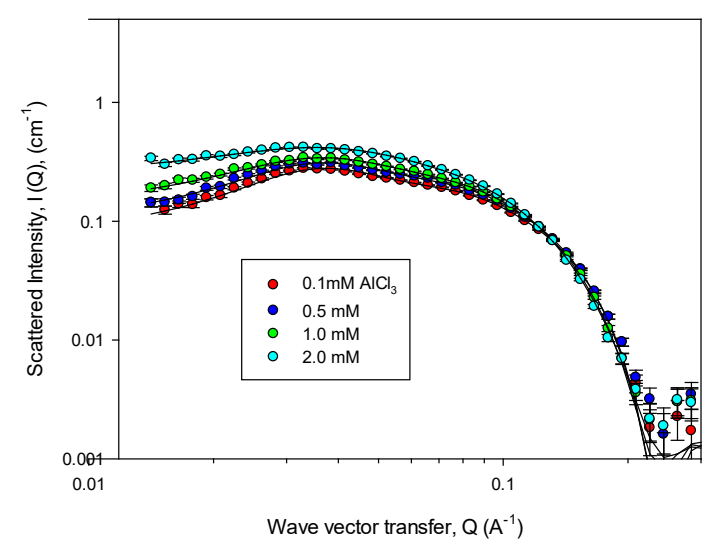

(b)

(c)

Figure 4. Scattered Intensity, $I(Q)$, versus wave vector transfer, $Q$, for $10 \mathrm{mM}$ surfactant in $\mathrm{AlCl}_{3}$, (a) $\mathrm{C}_{14} \mathrm{MES}$, (b) $C_{14} E E S$, and (c) $C_{16} E E S$, see legend for details. The solid lines are model calculations for the model described in the text and the key model parameters summarised in table 2 and tables $S 5$ in the Supporting Information. The data in figure $4 a$ are shifted vertically with respect to the previous plots by a factor 2 .

The SANS data, at $\mathrm{AlCl}_{3}$ concentrations below the onset of precipitation, are analysed quantitatively using the core + shell model for globular interacting micelles, as described previously, and the key fitting parameters are summarised in table 2 and in table S3 in the Supporting Information.

(a) $C_{14} M E S$ 


\begin{tabular}{|c|c|c|c|c|c|}
\hline $\begin{array}{c}\mathbf{A l C l}_{\mathbf{3}} \\
\text { concentration } \\
(\mathbf{m M})\end{array}$ & $\begin{array}{c}\text { Aggregation } \\
\text { number, } \mathbf{v}, \\
\pm \mathbf{5}\end{array}$ & $\begin{array}{c}\text { Micelle } \\
\text { charge, } \mathbf{z}, \\
\pm \mathbf{3}\end{array}$ & $\begin{array}{c}\text { Degree of } \\
\text { ionisation, } \\
\boldsymbol{\delta}, \pm \mathbf{0 . 0 3}\end{array}$ & $\begin{array}{c}\text { Ellipticity, } \\
\mathbf{e e ,} \pm \mathbf{0 . 0 2}\end{array}$ & $\begin{array}{c}\text { Scale } \\
\text { factor, } \mathbf{s f}\end{array}$ \\
\hline 0.01 & 64 & 16 & 0.25 & 1.07 & 1.07 \\
\hline 0.05 & 66 & 19 & 0.29 & 1.11 & 1.10 \\
\hline 0.1 & 68 & 17 & 0.25 & 1.15 & 1.08 \\
\hline 0.5 & 73 & 18 & 0.25 & 1.22 & 1.04 \\
\hline 1.0 & 85 & 20 & 0.24 & 1.42 & 1.21 \\
\hline
\end{tabular}

(b) $C_{14} E E S$

\begin{tabular}{|c|c|c|c|c|c|}
\hline $\begin{array}{c}\text { AlCl } \\
\text { concentration } \\
(\mathbf{m M})\end{array}$ & $\begin{array}{c}\text { Aggregation } \\
\text { number, } \mathbf{v}, \\
\pm \mathbf{5}\end{array}$ & $\begin{array}{c}\text { Micelle } \\
\text { charge, } \mathbf{z}, \\
\mathbf{\pm 3}\end{array}$ & $\begin{array}{c}\text { Degree of } \\
\text { ionisation, } \\
\boldsymbol{\delta}, \pm \mathbf{0 . 0 3}\end{array}$ & $\begin{array}{c}\text { Ellipticity, } \\
\mathbf{e e ,} \pm \mathbf{0 . 0 2}\end{array}$ & $\begin{array}{c}\text { Scale } \\
\text { factor, } \mathbf{s f}\end{array}$ \\
\hline 0.1 & 70 & 30 & 0.43 & 1.18 & 1.04 \\
\hline 0.5 & 76 & 29 & 0.38 & 1.26 & 0.99 \\
\hline 1.0 & 83 & 32 & 0.39 & 1.43 & 0.97 \\
\hline 2.0 & 104 & 19 & 0.18 & 1.74 & 0.91 \\
\hline
\end{tabular}

(c) $C_{16} E E S$

\begin{tabular}{|c|c|c|c|c|c|}
\hline $\begin{array}{c}\mathbf{A l C l}_{\mathbf{3}} \\
\text { concentration } \\
(\mathbf{m M})\end{array}$ & $\begin{array}{c}\text { Aggregation } \\
\text { number, } \mathbf{v}, \\
\pm \mathbf{5}\end{array}$ & $\begin{array}{c}\text { Micelle } \\
\text { charge, } \mathbf{z}, \\
\mathbf{\pm 3}\end{array}$ & $\begin{array}{c}\text { Degree of } \\
\text { ionisation, } \\
\boldsymbol{\delta}, \pm \mathbf{0 . 0 3}\end{array}$ & $\begin{array}{c}\text { Ellipticity, } \\
\mathbf{e e , ~} \pm \mathbf{0 . 0 2}\end{array}$ & $\begin{array}{c}\text { Scale } \\
\text { factor, } \mathbf{s f}\end{array}$ \\
\hline 0.1 & 98 & 57 & 0.58 & 1.24 & 0.90 \\
\hline 0.5 & 108 & 48 & 0.44 & 1.37 & 0.88 \\
\hline 1.0 & 122 & 32 & 0.31 & 1.55 & 0.91 \\
\hline 2.0 & 149 & 25 & 0.17 & 1.89 & 0.90 \\
\hline
\end{tabular}

Table 2. Key model parameters for $10 \mathrm{mM}$ surfactant in $\mathrm{AlCl}_{3}$, (a) $C_{14} \mathrm{MES}$, (b) $C_{14} E E S$, and (c) $C_{16} E E S$. 
The data in figure 4 and the key model parameters in table 2 and table S5 in the Supporting Information show that in general the micellar growth with the addition of $\mathrm{AlCl}_{3}$ up to the point of precipitation is relatively modest. The variation in the micelle aggregation number with $\mathrm{AlCl}_{3}$ concentration for the surfactant concentrations of 5,10 , and $20 \mathrm{mM}$ for all the five surfactants studied is summarised in figure 5.

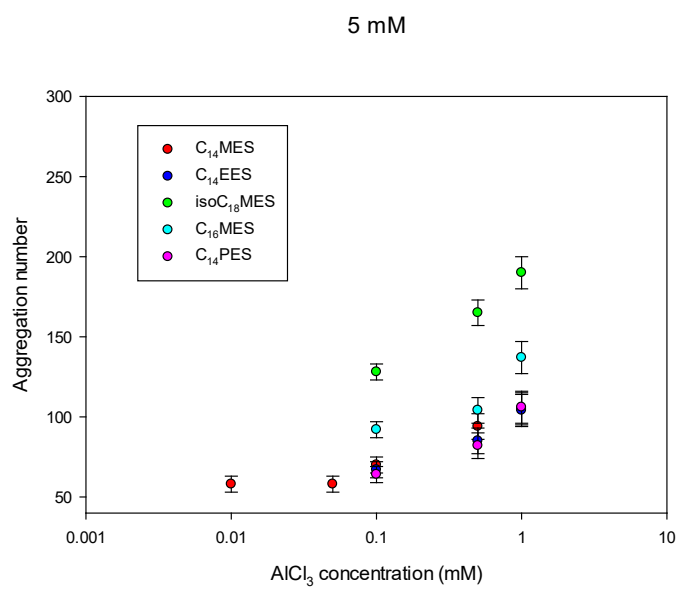

(a)

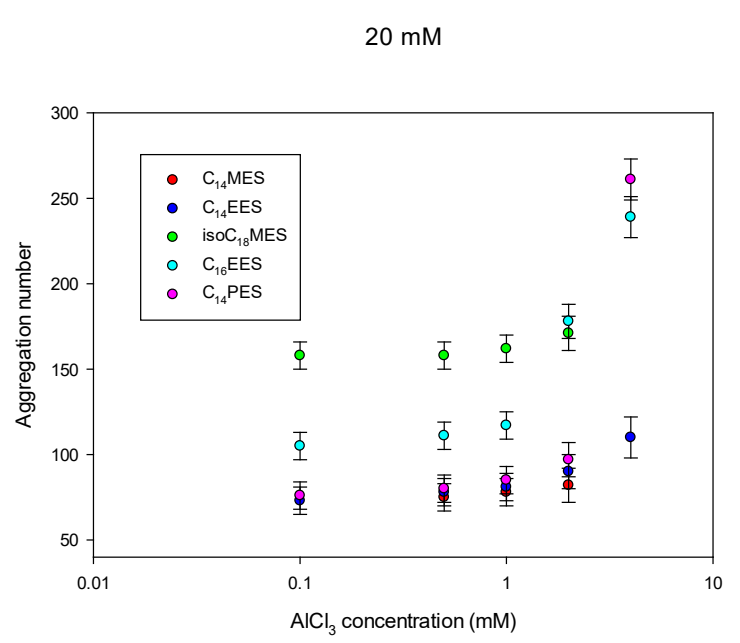

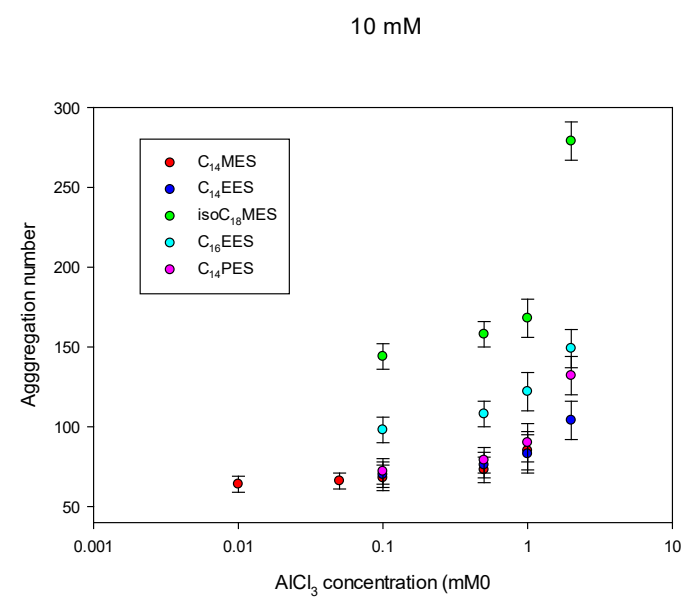

(b)

(c)

Figure 5. Variation in micelle aggregation number with $\mathrm{AlCl}_{3}$ concentration for the surfactant concentrations (a) $5 \mathrm{mM}$, (b) $10 \mathrm{mM}$, (c) $20 \mathrm{mM}$; see legend for details

As observed in the presence of $\mathrm{NaCl}$ the micellar growth with the addition of $\mathrm{AlCl}_{3}$ is more pronounced for the longer alkyl chain surfactants, $\mathrm{C}_{16} \mathrm{EES}$ and iso $\mathrm{C}_{18} \mathrm{MES}$. 
The 3-D structures have been visualised using the Autodesk 3-D software package, 3DSMAX, and figure 6 illustrates the variation in the structure for $20 \mathrm{mM} \mathrm{C}_{14} \mathrm{PES}$ in water, $100 \mathrm{mM} \mathrm{NaCl}$ and $4 \mathrm{mM} \mathrm{AlCl}_{3}$, as the micelle evolves from an aggregation number of 76 in water to 152 in $100 \mathrm{mM} \mathrm{NaCl}$ and 261 in $4 \mathrm{mM} \mathrm{AlCl}_{3}$.

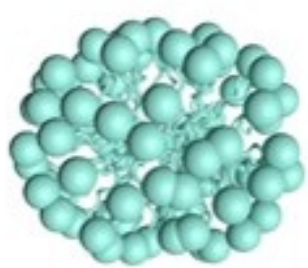

(a)

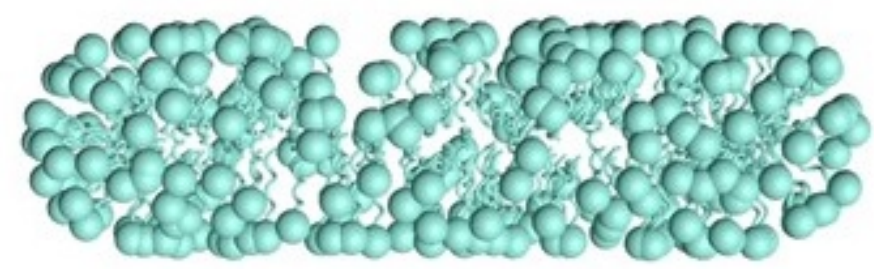

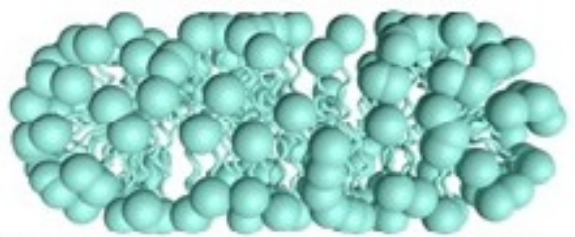

(b)

(c)

Figure 6. 3-D structures for $20 \mathrm{mM} C_{14} \mathrm{PES}$, (a) in pure water, (b) $100 \mathrm{mM} \mathrm{NaCl}$, and (c) 4 $\mathrm{mM} \mathrm{AlCl}$; for the model parameters defining the dimensions, ellipticity and aggregation number, in tables S1, S3 and S5 in the Supporting Information.

\section{DISCUSSION}

\section{(i) Micelle size in the absence of electrolyte}

The variation in the aggregation number with surfactant concentration is modest over the relatively small concentration range explored. This is not unexpected and compares with the variation over a similar concentration range for SDS (72). For SDS the aggregation number variation reported by Chen et al (72) was in the range 60 to 75 for surfactant concentrations from 10 to $20 \mathrm{mM}$. This compares with a similar variation of 60 to 75 for $\mathrm{C}_{14} \mathrm{MES}, \mathrm{C}_{14} \mathrm{EES}$ and $\mathrm{C}_{14} \mathrm{PES}$, as presented here. For the SAES surfactants (64) the variation in the micelle 
aggregation number over the same concentration range was slightly larger, from $\sim 65$ to $\sim 85$. In that study changing the degree of ethoxylation from 1 to 3 for the SLES surfactants had little impact upon the variation with concentration. This is similar to the observation reported here for the ester sulfonate surfactants as the size of the ester group is increased.

In the context of the packing criteria derived by Israelachivili et al (73), the micelle parameters for the AES surfactants are consistent with simple packing arguments. The Israelachivili, Ninham and Mitchel (73) packing parameter, pp, is defined as $\mathrm{pp}=\mathrm{V} / \mathrm{Al}$, where $\mathrm{V}$ is the alkyl chain volume, A the area/molecule, and 1 the fully extended chain length. For $\mathrm{pp}<1 / 3$ small globular micelles exist, for $1 / 3>\mathrm{pp}<1 / 2$ more elongated structures form, and for $\mathrm{pp}>1 / 2$ planar structures exist. For the $\mathrm{C}_{14}$ AES surfactants, assuming $\mathrm{V}=330 \AA^{3}, \mathrm{l}=17 \AA$ and $\mathrm{A}=50 \AA^{2}$, pp is $\sim 0.38$, just at the edge of the globular micellar region. It is known that changing the degree of esterification has little impact on the packing at the interface (53). It is therefore assumed here that $\mathrm{A}$ varies little, and hence pp will not substantially change. For the longer $\mathrm{C}_{16}$ and $\mathrm{C}_{18}$ alkyl chain length $\mathrm{A}$ is smaller, $\sim 45 \AA^{2}$, and 1 and $\mathrm{V}$ have increased respectively to 19 and $22 \AA$, and 380 and $430 \AA^{3}$. This now results in a pp value $\sim 0.44$, more completely in the region where elongation occurs. This is consistent with the observations for $\mathrm{C}_{16} \mathrm{EES}$ and iso $\mathrm{C}_{18} \mathrm{MES}$, where in the concentration range explored the aggregation numbers are 95 to 105 for $\mathrm{C}_{16} \mathrm{EES}$ and 150 for isoC ${ }_{18} \mathrm{MES}$.

\section{(ii) Micelle size in the presence of electrolyte}

The measurements in the presence of electrolyte were made in $\mathrm{NaCl}$ up to a concentration of $100 \mathrm{mM}$, and in $\mathrm{AlCl}_{3}$ at concentrations up to 2-5 mM. The concentration range of up to 100 $\mathrm{mM} \mathrm{NaCl}$ covers a range over which the electrostatic interaction between anionic surfactant micelles progresses to being effectively screened $(10,62,65-68,72)$. The concentration range explored with $\mathrm{AlCl}_{3}$ is lower and corresponds at the highest concentration to the upper limit at which precipitation into a concentrated lamellae phase occurs. It is also the concentration regime in which surface ordering occurs (49-53). It has been reported that the stronger binding of $\mathrm{Al}^{3+}$ compared to $\mathrm{Na}^{+}$results more effectively in the onset of precipitation (12-16), micellar growth, surface tension lowering (17-20) and surface ordering (49-53). However when the valency of the counterions is taken into account the relative electrolyte concentrations, $100 \mathrm{mM}$ $\mathrm{NaCl}$ and $2 \mathrm{mM} \mathrm{AlCl}_{3}$, are much closer when expressed in terms of the ionic strengths, $0.1 \mathrm{M}$ and $0.02 \mathrm{M}$ respectively, and this is a related factor to consider. 
Comparison of the increase in the micelle aggregation number in $100 \mathrm{mM} \mathrm{NaCl}$ and in the absence of electrolyte shows an increase for $\mathrm{C}_{14} \mathrm{MES}$ of $\sim 1.3$, whereas the increase for $\mathrm{C}_{14} \mathrm{EES}$, $\mathrm{C}_{14} \mathrm{PES}$ and $\mathrm{C}_{16} \mathrm{EES}$ is larger at $\sim 1.65$. For iso $\mathrm{C}_{18} \mathrm{MES}$ with the increase is more substantial at $\sim 4$.4. The increases in the aggregation number encountered in this range of surfactant and $\mathrm{NaCl}$ concentrations are broadly similar to those observed for SDS and other ionic surfactants $(10,62)$. It is known that $\mathrm{Al}^{3+}$ has a greater impact on micellar growth, as reported by Alargova et al $(17-19)$. This was also reported 6 by Xu et al $(52,64)$ for a range of SAES surfactants and different trivalent counterions. For the SAES molecules the presence of trivalent counterions resulted in a greater micelle growth before lamellar formation, with aggregation numbers up to $\sim 1000$, than is encountered here for the AES surfactants. For the AES surfactants the average micellar growth increases from $\sim 1.3$ to $\sim 2.0$, as the $\mathrm{AlCl}_{3}$ concentration increases up to $2 \mathrm{mM}$, and the degree of growth depends upon the detailed molecular structure. The growth is comparable for $\mathrm{C}_{14} \mathrm{MES}, \mathrm{C}_{14} \mathrm{EES}$ and $\mathrm{C}_{14} \mathrm{PES}$, and larger for $\mathrm{C}_{16} \mathrm{EES}$ and iso $\mathrm{C}_{18} \mathrm{MES}$. Lim et al (8) observed an improved detergency performance for MES in hard water compared to LAS. It was attributed to the structural characteristics of the MES surfactant, allowing MES to be relatively insensitive towards polyvalent ions such as $\mathrm{Ca}^{2+}$ and $\mathrm{Mg}^{2+}$ due to the weaker binding of the multivalent ions. Their rationale is consistent with the observations on micellar growth reported here.

For the SAES surfactants the micellar growth in the presence of $\mathrm{AlCl}_{3}$ depended upon the degree of ethoxylation, the surfactant concentration, and the alkyl chain length (52-64). It was more pronounced for the lower degrees of ethoxylation, 1 and 2 ethylene oxide groups compared with 3 at the intermediate surfactant concentration of $10 \mathrm{mM}$. This was explained as due to the increased steric hindrance of the larger ethylene oxide group, which inhibits micellar growth, and the associated $\mathrm{Al}^{3+}$ binding. It was also more pronounced for the longer $\mathrm{C}_{14}$ and $\mathrm{C}_{16}$ alkyl chain lengths (52) and for other trivalent counterions, $\mathrm{Cr}^{3+}$ and $\mathrm{Sc}^{3+}(64)$. The micellar growth in the presence of $\mathrm{Sc}^{3+}$ was more pronounced compared with $\mathrm{Al}^{3+}$, and this was attributed to an increased binding of $\mathrm{Sc}^{3+}$ compared to $\mathrm{Al}^{3+}$. For $\mathrm{Cr}^{3+}$ the micellar growth was less pronounced than for $\mathrm{Al}^{3+}$, and this was attributed to a weaker headgroup- $\mathrm{Cr}^{3+}$ interaction due to the shielding by the less labile hydration shell of $\mathrm{Cr}^{3+}$. However in all case the micellar growth for the SAES surfactants is significantly greater than encountered for the AES surfactants presented here. Although the micellar growth in the presence of $\mathrm{Al}^{3+}$ is not substantial and is even less pronounced than in the presence of $\mathrm{NaCl}$, there are nevertheless some discernible trends. Thus, the growth is most pronounced for the longer alkyl chain 
lengths, $\mathrm{C}_{16} \mathrm{EES}$ and iso $\mathrm{C}_{18} \mathrm{MES}$. For the $\mathrm{C}_{14}$ surfactants with differing ester groups the growth is similar for methyl, ethyl and propyl, and is not significant. This implies that the ester group inhibits the strong $\mathrm{Al}^{3+}$ binding and the bridging between neighbouring surfactant ions, but this does not depend upon the size of the ester group. The lack of strong $\mathrm{Al}^{3+}$ binding blocks the mechanism that reduces the area/molecule required to drive elongation. However, although the addition of $\mathrm{Al}^{3+}$ does not promote significant micellar growth, the onset of precipitation occurs at similar $\mathrm{Al}^{3+}$. concentrations to those reported for the SAES surfactants $(52,64)$.

\section{(iii) Micelle charge and counterion binding}

Although the trends in the data and their associated analysis are relatively clear, there is always some interplay between $\mathrm{S}(\mathrm{Q})$ and $\mathrm{P}(\mathrm{Q})$ which can affect an accurate determination of the surface charge on the micelle. At low $Q$ the decrease in the scattered intensity is determined by the form of $\mathrm{S}(\mathrm{Q})$, and the form factor $\mathrm{F}(\mathrm{Q})$ plays a secondary role. However as the micelle elongates the form factor becomes more significant at low $Q$ and the contribution from $S(Q)$ less so. This results in the significant increase in the scattered intensity at low $Q$ when there is substantial micellar growth. In the data presented here, the contribution from $S(Q)$ generally remains significant (see for example the data in figure $4 \mathrm{~b}$ and $\mathrm{c}$ ), and so the trends discerned in the degree of counterion binding are significant.

The general trends in the micelle charge with surfactant and electrolyte concentration presented here are consistent with the law of mass action for micellisation (67) and specific treatments of counterion binding (68), such as the dressed micelle model(66). That is, at concentrations close to the cmc the micelles are highly charged and as the micelle concentration increases the degree of ionisation decreases. The addition of electrolyte also results in a decrease in the degree of ionisation, although it is not always as pronounced as the variation with surfactant concentration (66).

In the presence of increasing amounts of $\mathrm{NaCl}$ the charge on the micelle surface decreases as the degree of counterion binding increases $(62,66)$. This is observed here for the $\mathrm{C}_{14} \mathrm{MES}$ surfactant as the $\mathrm{NaCl}$ concentration increases, as illustrated in table $\mathrm{S} 2$ in the Supporting Information. For $\mathrm{NaCl}$ concentrations greater than $0.05 \mathrm{M}$ a net charge is no longer discernible in the analysis of the SANS data. This would normally be associated with significant micellar growth, but that is not evident here. For the other AES surfactants investigated, the measurements in $100 \mathrm{mM} \mathrm{NaCl}$ and at different surfactant concentrations, see tables $\mathrm{S} 3$ in the Supporting Information, show that the degree of $\mathrm{Na}^{+}$binding is also high, but that it now 
coincides with a greater degree of micellar growth. The data in the presence of $\mathrm{AlCl}_{3}$ again shows that as the $\mathrm{AlCl}_{3}$ concentration increases the degree of ionisation decreases (see table S5 in the Supporting Information). However in that case there is still a significant degree of ionisation at the highest $\mathrm{AlCl}_{3}$ concentrations measured, and it reduces to a value in the range $\sim 0.1$ to 0.2 , depending upon the surfactant type. This supports the idea that the $\mathrm{Al}^{3+}$ binding is not as strong as that of $\mathrm{Na}^{+}$, and that this in part explains the increased reluctance for micellar growth.

The other main contribution factor to the relatively modest change in aggregation number with surfactant concentration and electrolyte concentration / type, even though in some cases the micelle charge is varying significantly, also arises from the headgroup structure. As discussed earlier, in the context of the molecular thermodynamic treatment of the free energy of micellisation $(69,70)$ the two main headgroup contributions are electrostatic and steric $(69$, 70). The results here imply that not only is the electrostatic contribution and the strength of counterion binding affected by the headgroup esterification, but that the steric contribution to the free energy of micellisation is dominant.

Alargova et al (17-19) studied the micellar growth in the anionic surfactant $\mathrm{SLE}_{2} \mathrm{~S}$ in the presence of $\mathrm{AlCl}_{3}$, by surface tension and dynamic light scattering. Importantly they demonstrated that the onset of significant micellar growth, from spheres to rods, coincided with the $\mathrm{Al}^{3+}$ charge being in excess. This was defined by the parameter $\xi$, where $\xi=\left(\mathrm{C}_{\mathrm{s}}-\mathrm{cmc}\right) /$ $3 \mathrm{C}_{\mathrm{Al}}, \mathrm{C}_{\mathrm{s}}$ is the surfactant concentration and $\mathrm{C}_{\mathrm{Al}}$ the $\mathrm{Al}^{3+}$ concentration; so that for $\xi<1.0$ the $\mathrm{Al}^{3+}$ charge is in excess. This also coincided with a significant decrease in the associated surface tension data, and they developed a theoretical treatment of the surface tension data based on the relative binding strengths of $\mathrm{Na}^{+}$and $\mathrm{Al}^{3+}$. Although no similar pronounced threshold is observed here, our results also reinforce the importance of the relative binding of $\mathrm{Na}^{+}$and $\mathrm{Al}^{3+}$ and highlight how changes in the headgroup structure can alter that balance.

In a recent molecular dynamics study $\mathrm{Chen}$ and $\mathrm{Xu}(74)$ compared the $\mathrm{Ca}^{2+}$ binding to SDS and LAS, and demonstrated that the introduction of the EO group in the SLES surfactants and the sodium dodecyl benzene oxyethylene sulfate, LAES, surfactants results in a binding of $\mathrm{Ca}^{2+}$ to the EO group and a weakening in the binding to the $\mathrm{SO}_{3}{ }^{-}$group. This mechanism was attributed to the reduction in the trend towards precipitation in the presence of $\mathrm{Ca}^{2+}$ for LAS compared with SDS and LAS. That study further highlights how changes in the headgroup structure can significantly affect ion binding mechanisms. 


\section{(iv) Relationship between micelle growth and surface ordering}

The weakness of micellar growth with $\mathrm{Al}^{3+}$ correlates with the surface behaviour in the presence of $\mathrm{Al}^{3+}$. The SAES and $\mathrm{C}_{14} \mathrm{MES}$ surfactants all exhibit a complex but reproducible transition from monolayer to increasingly ordered layered structures at the interface, culminating in extended multilayer structures at the interface in the presence of increasing $\mathrm{Al}^{3+}$ concentrations $(42-45,49-53)$. For the $\mathrm{C}_{14} \mathrm{EES}, \mathrm{C}_{14} \mathrm{PES}$ and $\mathrm{C}_{16} \mathrm{EES}$ surfactants (53) the only transition encountered as the $\mathrm{AlCl}_{3}$ concentration is increased is the transition from monolayer adsorption to a monolayer + bilayer structure, $S_{1}$ in the terminology previously used (53), and the more extended multilayer structures are not encountered, up to relatively high $\mathrm{AlCl}_{3}$ concentrations. This suggests that a weakening of the $\mathrm{Al}^{3+}$ binding results in both the less ordered surface properties and the weaker micelle growth. However from the analysis of the SANS data for the AES surfactants in the absence of electrolyte, the degree of ionisation deduced from the modelling is similar to other anionic surfactants, such as SDS, and does not imply any significant change in the $\mathrm{Na}^{+}$binding. Hence the structural impact of the headgroup geometry must be very counterion dependent.

For the iso $\mathrm{C}_{18} \mathrm{MES}$ no surface ordering is observed in the presence of $\mathrm{AlCl}_{3}$, and this implies that alkyl chain branching is an additional factor in the inhibition of more ordered surface structures and micelle growth.

This study and related studies $(47,52,64)$ illustrate that changes in the relative binding of $\mathrm{Na}^{+}$ and $\mathrm{Al}^{3+}$ can be affected by changes in the headgroup structure. It also implies that such changes are responsible for the weakness of micellar growth in the presence of electrolyte presented here, and in the less pronounced surface ordering encountered (53). However, these changes in headgroup structure do not substantially affect the onset of the formation of a concentrated lamellar phase and precipitation, and this indicates also that other factors which are not identified here are important. Comparison with the self-assembly behaviour of the SAES surfactants in the presence of different multivalent counterions reinforces this observation. In the self-assembly of the SLES molecules with different multivalent counterions, it was observed that the weaker binding of $\mathrm{Cr}^{3+}$ resulted, as expected, in both a less substantial micellar growth and a shift in the onset of surface multi- lamellar formation to higher $\mathrm{Cr}^{3+}$ concentrations (52). 


\section{CONCLUSIONS}

SANS has been used to characterise the micellar properties of a range of AES surfactants with different alkyl chain length and differing degrees of esterification. The results show that relatively small globular micelles form, and that the degree of esterification of the headgroup has relatively little impact upon the micelle size. In contrast, increasing the alkyl chain length results in consistently larger micelles, which can be described as modestly anisotropic ellipsoids. The results are compared with those of other related ionic surfactant micelles (44, $52,62,64,67)$. In the presence of $\mathrm{NaCl}$ and $\mathrm{AlCl}_{3}$ only relatively modest micellar growth occurs before the onset of precipitation, in the case of $\mathrm{AlCl}_{3}$. This growth is more significant in the presence of $\mathrm{NaCl}$, and for the longer alkyl chain length surfactants. The modest micellar growth, especially in the presence of $\mathrm{AlCl}_{3}$, contrasts with more significant growth observed in related systems $(17-19,49,52,64)$, and is attributed to the relative binding strengths of $\mathrm{Na}^{+}$ and $\mathrm{Al}^{3+}$ to the esterified headgroups. It is normally observed that the $\mathrm{Al}^{3+}$ binding is stronger than the $\mathrm{Na}^{+}$binding, and this implies that the ester groups influence the binding of the bulkier $\mathrm{Al}^{3+}$ counterion. The relative modest growth also implies that the headgroup steric contribution to the free energy of micellisation dominates over the electrostatic contribution. The modest micellar growth observed in the self-assembly in the presence of $\mathrm{Al}^{3+}$ correlates with the absence of the more extensive multilayer formation reported at the air-water interface (53) in the presence of multivalent counterions. Hence the weaker binding of $\mathrm{Al}^{3+}$ and the steric constraints associated with the ester groups in the headgroup region limit the packing required for more extensive multilayer formation at the interface. The results have important implications in the context of formulations involving the AES surfactants and the manipulation of their bulk rheological properties, which are often seen as an important factor in product delivery and performance. Finally the results also point to the possibility of manipulating the headgroup structure to control the surface as well as the bulk properties, and should in a wider context be further explored using different structures and mixtures of structures.

\section{ACKNOWLEDGEMENTS}

The provision of neutron beam time at the ISIS neutron beam facility, and for the excellent scientific and technical support is acknowledged. The specially synthesised surfactants were provided by the ISIS Deuteration Facility. The authors thank the China Scholarship Council, $\mathrm{CSC}$, for their financial support. 


\section{SUPPORTING INFORMATION}

The Supporting Information contains an additional plot of the scattering data, and tables of the key model parameters. 


\section{REFERENCES}

(1) J J Scheibel, The evolution of anionic surfactant technology to meet the requirements of the laundry detergent industry, J. Surf. Det., 2004, 7, 319-328

(2) Y U Yangxin, Z Jin, A E Bayley, Development of surfactants and builders in detergent formulations, Chin. J. Chem. Eng. 2008, 16, 517-527

(3) P Foley, A Kermanshahi pour, E S Beach, J B Zimmerman, Derivation and synthesis of renewable surfactants, Chem. Soc. Rev. 2012, 41, 1499-1518

(4) K Holmberg, Natural Surfactants, Curr. Opin. Coll. Int. Sci. 2001, 6, 148-159

(5) S De, A Malik, A Ghosh, R Saha, B Saha, A review on natural surfactants, J. Taiwan Int. Chem. Eng. 2015, 81, 65757-65767

(6) D G Hayer, D K Solaiman, R D Ashby, Biobased surfactants: synthesis, properties, and applications, Academic and AOCS Press, 2019, $2^{\text {nd }}$ Edition

(7) J Aparicio, B W MacArthur, W B Sheats, B J Brooks, MES myths, mysteries and perspectives on properties and use, ICSD, Shangai, PRC, 2012

(8) Y S Lim, N B Baharudin, Y W Ung, Methyl ester sulfonates: a high performance surfactant capable of reducing builder dosage, J. Surf. Det. 2019, 22, 549-558

(9) N M van Os, J R Haak, L A M Rupert, Physico-chemical properties of selected anionic, cationic and non-ionic surfactants, Elsevier, Amsterdam, 1993

(10) P J Missel, N A Mazer, M C Carey, G B Benedek, Influence of alkali metal counterions on the sphere to rod transition in alkyl sulfate micelles, J. Phys. Chem. $1989,93,8354-8366$

(11) M J Rosen, Surfactants and Interfacial phenomena, J Wiley and Sons, New York, 1989

(12) P Somasundaran, K P Ananthapudmanbhan, M S Celik, Precipitation and redissolution phenomena in sulfonate $-\mathrm{AlCl}_{3}$ solutions, Langmuir, 1988, 5, 1061-1063

(13) P Paton-Morales, F I Talens-Alesson, Effect of ionic strength and competitive adsorption of $\mathrm{Na}^{+}$in flocculation of lauryl sulfate micelles with $\mathrm{Al}^{3+}$, Langmuir, $2001,17,6059-6062$

(14) K L Steller, J F Scamehorn, Surfactant precipitation in aqueous solutions containing mixtures of anionic and non-ionic surfactants, J. Am. Chem. Soc. 1986, $63,566-574$ 
J F Scamehorn, S D Christian, R T Ellington, in Surfactant based separation, Eds, J F Scamehorn, J H Harwell, Surfactant Science Series, Vol 33, Marcel Dekker, New York, 1989

(16) S L Chou, J H Bae, Surfactant precipitation and re-dissolution in brine, J. Coll. Int. Sci. 1983, 96, 192-203

(17) R G Alargova, K D Danov, J T Petkov, P A Kralchevsky, G Broze, A Mahreteab, A sphere-rod transition in the shape of anionic micelles determined by surface tension measurements, Langmuir, 1997, 13, 5544-5551

R G Alargova, K D Danov, P A Kralchevsky, G Broze, A Mahreteab, Growth of giant rod-like micelles of ionic surfactants in the presence of $\mathrm{Al}^{3+}$ counterions, Langmuir, 1998, 14, 4036-4049

(19) R G Alargova, J T Petkov, D N Petsev, Micellisation and interfacial properties of the alkyloxyethylene sulfate surfactants in the presence of multivalent counterions, J. Coll. Int. Sci. 2003, 261, 1-11

(20) $\mathrm{J} \mathrm{H} \mathrm{Mu}, \mathrm{G} \mathrm{Z} \mathrm{Zi,} \mathrm{Rheology} \mathrm{of} \mathrm{viscoelastic} \mathrm{anionic} \mathrm{micelle} \mathrm{solutions} \mathrm{in} \mathrm{the}$ presence of multivalent counterions, Coll. Polym. Sci. 2001, 279, 872-875

(21) K D Danov, P A Stanimirova, P A Kralchevsky, E S Basheva, V I Ivanova, J T Petkov, Sulfonated methyl esters of fatty acids in aqueous solution: interfacial and micellar properties, J. Coll. Int. Sci. 2015, 457, 307-318

(22) Z A Maurad, R Ghazali, P Siwayanan, Z Ismail, A Ahmad, Apha-sulfonated methyl esters as an active ingredient in palm oil based powder detergents, J. Surf. Det. $2006,9,161-166$

(23) L Cohen, F Soto, A Melgarejo, D W Roberts, Performance of $\Phi$-sulfo fatty methyl ester sulfonate versus alkyl benzene sulfonate secondary alkane surfactants and $\alpha$-sulfo fatty methyl ester sulfonates, J. Surf. Det. 2008, 11, 181-186

(24) D W Roberts, Aquatic toxicity: are surfactant properties relevant, J. Sur. Det. 2000, 3, 309-315

(25) R Ghazali, Z A Maurad, P Siwayanan, M Yusef, A Ahmed, Assessment of aquatic effects of palm based alpha sulfonated methyl esters, J. Oil Palm Res. 2006, $18,225-230$

(26) R Ghazali, A Ahmed, Biodegradability and ecotoxicity of palm stearin based methyl ester sulfonates, J. Oil Palm Res. 2004, 16, 39-44

(27) R Ghazali, The effect of salt on the biodegradability of methyl ester sulfonates, J. Oil Palm Res. 2002, 14. 45-50 

methyl esters as a route for the production of surfactant feedstocks, Inform, 2007, 18, 216-220

(29) P Siwayanan, R Aziz, N A Bakar, H Ya, R Jokiman, S Chelliapan, detergent stability and particle characterisation of phosphate free spray dried detergent powders incorporated with palm $\mathrm{C}_{16} \mathrm{MES}$, J. Oleo Sco. 2014, 63, 585-592

P Siwayanan, R Aziz, N A Bakar, H Ya, R Jokiman, S Chelliapan, Characterisation of phosphate free detergent powders incorporating palm $\mathrm{C}_{16}$ methyl ester sulfonates ( $\left.\mathrm{C}_{16} \mathrm{MES}\right)$ and linear alkyl benzene sulfonic acid (LBSA), J. Surf. Det. $2014,17,871-880$

(31) Z Maurad, Z Idris, R Ghazali, Performance of palm based $\mathrm{C}_{16} / \mathrm{C}_{18}$ methyl ester sulfonate (MES) in liquid detergent formulation, J. Oleo Sci. 2017, 66, 1-11

(32) L Cohen, F Trujillo, Synthesis, characterisation and surface properties of sulfonated methyl esters, J. Surf. Det. 1998, 1, 335-341

(33) L Cohen, F Sota, M S Imura, Separation and extraction of $\Phi$ - methyl ester sulfonates: new features. J. Surf. Det. 2001, 4, 73-74

(34) W Stein, H Baumann, $\alpha$-sulfonated fatty acids and esters: manufacturing process, properties and applications, JAOCS, 1975, 52, 323-329

(35) K Ohbu, M Fujwara, Y Abe, Physico-chemical properties of $\alpha$-sulfonated fatty acid esters, Prog. Coll. Polym. Sci. 1998, 109, 85-92

(36) S P Wong, W H Lin, S F Chen, C H Chuak, Properties of sodium methyl ester $\alpha$-sulfo/ trimethyl ammonium bromide mixtures, J. Surf. Det. 2012, 15, 601-611

(37) Slamet, M Ibadurrohman, P P Wulandar, Synthesis of methyl ester sulfonate surfactants from crude palm oil as an active substance of laundry liquid detergents, |AIP Conf. Proc. 2017, 1904, 0250058

(38) P L Permadani, M Ibadurrohman, Slamet, Utilisation of waster cooking oil as a raw material for synthesis of methyl ester sulfonate (MES) surfactants, IOP Conf. Ser. : Earth and Environ. Sci. 2018, 105, 012036

(39) Y Jin, S Tian, J Guo, X Ren, X Li, S Gao, Synthesis, characterisation and explorative applications of anionic surfactant fatty acid methyl ester sulfonate from waste cooking oil, J. Surf. Det. 2016, 19, 467-475

(40) N Saxena, N Dai, S Dey, A Mandal, Surfactant synthesis from palm oil and its applications in enhanced oil recovery, J. Taiwan Ints. Chem. Eng. 2017, 81, 343-355 

$1453-1465$

(42) R K Thomas, J Penfold, H Xu, P X Li, K Ma, D W Roberts, J Petkov, R Welbourne, Adsorption of methyl ester sulfonate at the air-water interface: can limitations in the application of the Gibbs equation be overcome by 'computer purification', Langmuir, 2017, 33, 9944-9953

H Xu, R K Thomas, J Penfold, P X Li, K Ma, R Welbourne, D W Roberts, J T Petkov, The impact of electrolyte on the adsorption of the anionic surfactant methyl ester sulfonate at the air-solution interface: surface multilayer formation, J. Coll. Int. Sci. 2018, 512, 231-238

(44) H Xu, P X Li,K Ma, R Welbourne, J Doutch, J Penfold, R K Thomas, D W Roberts, J T Petkov, K L Choo, S Y Khoo, Adsorption and self-assembly in methyl ester sulfonate surfactants, their eutectic mixtures and the role of electrolyte, J. Coll. Int. Sci. 2018, 516, 456-465

H Xu, P X Li, K Ma, R Welbourne, J Penfold, R K Thomas, D W Roberts, J T Petkov, The role of competitive counterion adsorption on the electrolyte induced surface ordering in the methyl ester sulfonate surfactants at the air-water interface, J. Coll. Int. Sci. 2019, 533, 154-160

(46) J Penfold, C C Dong, I Tucker, K Metcalfe, S Golding, I Grillo, Equilibrium surface adsorption behaviour in complex anionic / non-ionic surfactant mixtures, Langmuir, 2007, 23, 20240-20249

(47) J Penfold, R K Thomas, C C Dong, I Tucker, K Metcalfe, S Golding, I Grillo, Surface and solution properties of anionic / non-ionic surfactant mixtures of alkyl benzene sulfate and triethylene glycol decyl ether, Langmuir, 2010, 26, 10614-10626

(48) J Penfold, R K Thomas, C C Dong, I Tucker, K Metcalfe, S Golding, I Grillo, The adsorption and self-assembly of mixtures of alkyl benzene sulfate isomers and the role of divalent electrolyte, Langmuir, 2011, 27, 6674-6684

(49) J T Petkov, I M Tucker, J Penfold, R K Thomas, D N Petsev, C C Dong, S Golding, I Grillo, The impact of the multivalent counterion $\mathrm{Al}^{3+}$ on the surface adsorption and self-assembly of the alkyloxyethylene sulfate and anionic / non-ionic surfactant mixtures, Langmuir, 2010, 26, 16691-16709

(50) H Xu, J Penfold, R K Thomas, J T Petkov, I Tucker, J R P Webster, The formation of surface multilayers at the air-water interface from sodium polyethylene 
monoalkyl ether sulfate / $\mathrm{AlCl}_{3}$ solutions: the role of the size of the polyethylene oxide group, Langmuir, 2013, 29, 11656-11666

(51) $\mathrm{H} \mathrm{Xu}$, J Penfold, R K Thomas, J T Petkov, I Tucker, J R P Webster, The formation of surface multilayers at the air-water interface from sodium polyethylene glycol monoether sulfate, Langmuir, 2014, 30, 4694-4702

(52) H Xu, J Penfold, R K Thomas, J T Petkov, I Tucker, J R P Webster, I Grillo, Ion specific effects in trivalent counterion induced surface and solution self-assembly of the anionic surfactant sodium polyethylene glycol monododecyl ether sulfate, Langmuir, 2015, 15, 6773-6781

Z Wang, P X Li, K Ma, Y Chen, M Campana, J Penfold, R K Thomas, D W Roberts, H Xu, J T Petkov, Z Yan, Impact of molecular structure, headgroup and alkyl chain geometry, on the adsorption of the anionic ester sulfate surfactants at the air-water interface, in the presence and absence of electrolyte, J. Coll. Int. Sci. 2019, $544,293-302$

(54) L M Bergstrom, A Tehrani-Bagha, G Nagy, growth behaviour, geometrical shape and the second cmc of micelles formed by cationic gemini esterquat surfactants, Langmuir, 2015, 31, 4644-4653

K D Danov, P A Kralchevzky, S D Stoyanov, J L Cook, I P Scott, Analytical modelling of micellar growth. 1. Chain conformation free energy of binary mixed spherical, wormlike and lamellar micelles, J. Coll. Int. Sci. 2019, 547, 245-255

(56) G V Jensen, R Lund, J Gummel, T Narayanan, J S Perdersen, Monitoring the transition from spherical to polymer-like surfactant micelles using SAXS, Agnew. Chem. Int. Ed. 2014, 53, 11524-11528

(57) Z Liu, M Cao, Y Chen, Y Fan, D Wang, $\mathrm{H} \mathrm{Xu,} \mathrm{Y} \mathrm{Wang,} \mathrm{Interactions} \mathrm{of} \mathrm{divalent}$ and trivalent metal counterions with anionic sulfonate gemini surfactants and induced aggregate transitions in aqueous solution, J. Phys. Chem. B 2016, 120, 4102-4113

LOQ

Diffractometer

at

the

ISIS

Facility,

http://www.isis.stfc.ac.uk/instruments/LOQ/

http://www.isis.stfc.ac.uk/instruments/SANS2D/

(60) R K Heenan, S M King, R Osborn, H B Stanley, RAL internal report, RAL-89128,1989

(61) http://www.mantidproject.org/ 
(62) J B Hayter, J Penfold, Determination of micelle structure and charge by small angle neutron scattering, Coll Polym Sci, 1983, 26, 1022-1030

(63) J B Hayter, J P Hansen, A rescaled MSA structure factor for dilute charged colloidal dispersions, Mol Phys, 1982, 46,651-656

(64) H Xu, J Penfold R K Thomas, J T Petkov, I Tucker, I Grillo, A Terry, Impact of $\mathrm{AlCl}_{3}$ on the self-assembly of the anionic surfactant sodium polyethylene glycol monoalkyl ether sulfate in aqueous solution, Langmuir, 2013, 29, 13359-13360

(65) J Penfold, I Tucker, R K Thomas, E Staples, R Schuermann, The structure of mixed anionic / non-ionic surfactant micelles: experimental observations relating to the role of headgroup electrostatic and steric effects, and the effect of electrolyte, J. Phys. Chem. B, 2005, 109, 10760-10770

(66) J B Hayter, A self-consistent theory of dressed micelles, Langmuir, 1992, 8, 2873-2876

(67) A I Rusanov, The mass action law theory of micellar solutions, Adv. Coll. Int. Sci. $1993,45,1-78$

(68) E Ruckenstein, J A Beuren, Effect of counterion binding on micellisation, Langmuir, 1988, 4, 77-90

(69) S Puvvada, D Blankschtein, Thermodynamic description of micellisation, phase behaviour and phase separation in aqueous solutions of surfactant mixtures, J. Phys. Chem. 1992, 96, 5567-5579

(70) R Nagarajan, Molecular theory of mixed micelles, Langmuir, 1985, 1, 331-341

(71) J Penfold, I Tucker, R K Thomas, E Staples, R Schuermann, Structure of mixed anionic / nonionic surfactant micelles; experimental observations relating to the role of headgroup electrostatic and steric effects and the effects of added electrolyte, J. Phys. Chem. B 2005, 109, 10760-10770

(72) Z Chen, J Penfold, P Li, J Doutch, Y Fan, Y Wang, Effect of length and hydrophilicity / hydrophobicity of diamines on the self-assembly of diamine / SDS Gemini-like surfactants, Soft Matter, 2017, 13, 8980-8989

(73) J N Israelachivili, D J Mitchel, B W Ninham, Theory of self-assembly of hydrocarbon amphiphiles into micelles and bilayers, J. Chem. Soc. Faraday Trans 2, $1976,72,1525-1568$

(74) Y Chen, $\mathrm{G} \mathrm{Xu}$, Improvement of $\mathrm{Ca}^{2+}$ tolerance by the introduction of EO groups for anionic surfactants: molecular dynamics simulation, Coll. Surf. A, 2013, 424, 2632 